\title{
Image of a subsurface current core in the southern South China Sea
}

\author{
Q. S. Tang ${ }^{1}$, D. X. Wang ${ }^{2}$, J. B. Li ${ }^{3}$, P. Yan ${ }^{1}$, and J. $\mathbf{L i}^{2}$ \\ ${ }^{1}$ Key Laboratory of Marginal Sea Geology, South China Sea Institute of Oceanology, Chinese Academy of Sciences, \\ Guangzhou 510301, China \\ ${ }^{2}$ State Key Laboratory of Tropical Oceanography, South China Sea Institute of Oceanology, Chinese Academy of Sciences, \\ Guangzhou 510301, China \\ ${ }^{3}$ Key Laboratory of Submarine Geoscience, Second Institute of Oceanography, State Oceanic Administration, Hangzhou \\ 310012, China
}

Correspondence to: D. X. Wang (dxwang@scsio.ac.cn)

Received: 19 October 2012 - Published in Ocean Sci. Discuss.: 17 December 2012

Revised: 29 March 2013 - Accepted: 31 May 2013 - Published: 9 July 2013

\begin{abstract}
A legacy seismic transect acquired on 30 and 31 May 2009 in the southern South China Sea (SCS) was reprocessed to reveal the thermohaline structure of the water column. In the study region, a mesoscale subsurface lens with extraordinary features was detected at $113.5^{\circ} \mathrm{E}, 11.5^{\circ} \mathrm{N}$. It is centred at $450 \mathrm{~m}$ depth, occupies both the subsurface and intermediate water from 250 to $600 \mathrm{~m}$, and has an intersection diameter of around $60 \mathrm{~km}$. The simulated results from Hybrid Coordinate Ocean Model reveal an eddy-induced subsurface current running southwestward along the deep basin edge and suggest that the imaged lens is a snapshot of the subsurface current core rather than a subsurface eddy.
\end{abstract}

\section{Introduction}

A subsurface current (or undercurrent) is a type of current that runs below the ocean surface. Geographically, three main classes of undercurrents are often concerned: the Equatorial Undercurrents, the Western Boundary Undercurrents, and the Eastern Boundary Undercurrents (e.g. Lindstrom et al., 1987; Qu et al., 1997; Pierce et al., 2000; Montes et al., 2010). Like the current systems at the ocean surface, these subsurface currents also play an irreplaceable role in the ocean circulation, transport, mixing, and ecosystem. Since no extensive spatial observations, such as the satellite images, can be obtained, the subsurface currents are less understood. Recently, a new ocean observation technique, seismic oceanography, has been used to image the structures in the ocean interior with a high lateral resolution of $O(10 \mathrm{~m})$ (e.g.
Holbrook et al., 2003). Theoretically, a seismic image shows the derivative of acoustic impedance (product of density and velocity) of the water. Essentially, it is a smoothed map of vertical temperature gradient (Ruddick et al., 2009). Various oceanic phenomena, such as fronts, currents, boundaries, eddies, internal waves/tides, etc., have been successfully imaged in the global ocean (e.g. Holbrook and Fer, 2005; Holbrook et al., 2009; Ruddick et al., 2009; Tang and Zheng, 2011). Take the oceanic currents (surface and subsurface) for example, the seismic image can easily capture the weak differences between two water masses, and then confine the currents exactly from the reflective fronts or boundaries (e.g. Holbrook et al., 2003; Nandi et al., 2004; Nakamura et al., 2006; Buffett et al., 2009; Pinheiro et al., 2010; Quentel et al., 2010; Tang and Zheng, 2011; Vsemirnova et al., 2012).

The South China Sea (SCS) is the largest semi-enclosed marginal sea in the northwest Pacific. The upper-layer circulation of the SCS is mainly driven by the monsoon, with significant influence from the Kuroshio in the northern SCS (Qu, 2000). Its multi-eddy structure has been examined by numerous studies using traditional methods (e.g. Wang et al., 2003; Xiu et al., 2010; Nan et al., 2011). In contrast, as a cul-de-sac of the North Pacific Intermediate Water (NPIW), the SCS's intermediate layer circulation and mesoscale structures are seldom documented (e.g. Isobe and Namba, 2001; You et al., 2005; Xie et al., 2011). Numerical results by You et al. (2005) showed that the intermediate circulation is cyclonic in winter/spring and anticyclonic in summer/fall. The monsoon is also the primary forcing of the intermediate circulation. Observation data revealed a southward-verging 


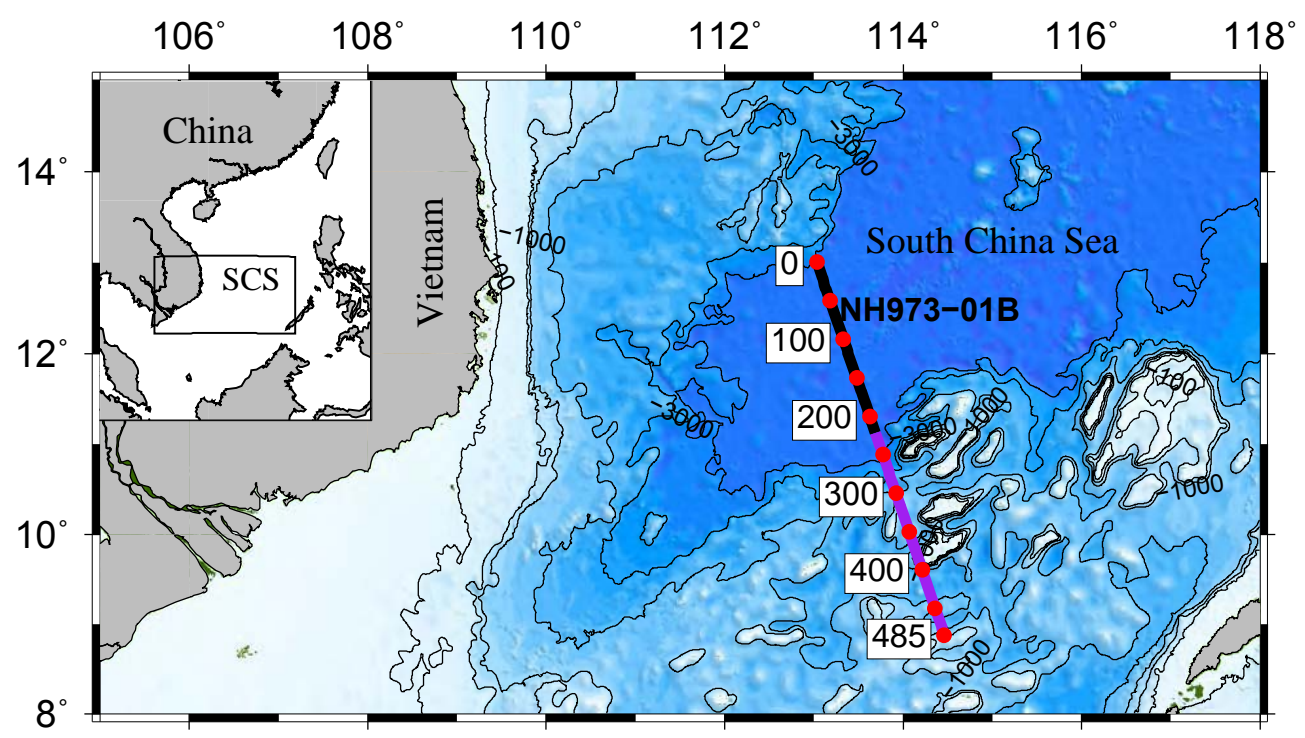

Fig. 1. Bathymetry of the southern South China Sea. The seismic line NH973-01B, labelled with distances (in units of km) from the starting point, is divided into two subsections. There is a time gap of $5 \mathrm{~h}$ at the line junction.

wedge of the low salinity anomaly between 400 and $700 \mathrm{~m}$ depth, indicating a southward spreading path of the NPIW (Wang et al., 2004). Xie et al. (2011) reported an anticyclonic eddy in the intermediate layer (500-900 m) of the Luzon Strait, which might be generated by both baroclinic instability and the interaction of the current with the bottom topography, rather than by the Kuroshio or the surface wind.

Mesoscale activities are also pervasive in the southern SCS (Fig. 1) because of the strong monsoon and rough topography. In the area, the circulation in summer is often characterized by a dipole flow pattern, in which a separated coastal jet (i.e. the Southeast Vietnam Offshore Current, SEVOC) is sandwiched by an anticyclonic circulation to the south and a cyclonic circulation to the north (Wang et al., 2006; Gan and $\mathrm{Qu}, 2008)$. Observational data shows that the vertical extent of the separated coastal jet is more than $300 \mathrm{~m}$ (Fang et al., 2002). A diagnostic calculation shows that the coastal jet is shallower than $500 \mathrm{~m}$, while the anticyclonic eddy reaches deeper than $500 \mathrm{~m}$ (Wang et al., 2004). Hu et al. (2011) studied the three-dimensional structure of the north part of the dipole, and found that the eddy extended downward for more than $250 \mathrm{~m}$ with a vertically heterogeneous structure. Although some studies suggested deep penetration of these eddies to the subsurface and intermediate layers in the SCS, most studies have referred to them as upper-layer-dominated features.

In this paper, we report a subsurface lens-like structure captured by a seismic survey in the southern SCS $\left(113.5^{\circ} \mathrm{E}\right.$, $\left.11.5^{\circ} \mathrm{N}\right)$ at the end of spring. Approximately, it was centred at $450 \mathrm{~m}$ depth, extending from $250 \mathrm{~m}$ to $600 \mathrm{~m}$ depth with an intersection diameter of $60 \mathrm{~km}$. Generally, such structures may be considered as subsurface eddies without further constraints (e.g. Sheen et al., 2009; Huang et al., 2010).
However, the high-resolution velocity field simulated from a global Hybrid Coordinate Ocean Model (HYCOM) suggests that the lens-like structure is more like a cross section of a subsurface current/flow, rather than a subsurface eddy as described by Huang et al. (2010).

\section{Data}

From 30 May to 1 June 2009, a seismic survey line labelled NH973-01B was carried out by the Guangzhou Marine Geological Survey of the Chinese Ministry of Land and Resources. The line traversed from the southwestern basin to the Spratly Islands region, with a vessel heading of $161^{\circ}$ (Fig. 1). Because of the strong streamer feathering (maximum $12.5^{\circ}$ ) during the data acquisition, the line was divided into two parts, the north and the south subsections, with a time gap of approximately $5 \mathrm{~h}$ from 04:01 to 09:17 on 31 May 2009 at the line junction. The source was composed of 4 arrays of BOLT guns (total volume of $83 \mathrm{~L}$ ) that were triggered every $37.5 \mathrm{~m}$. The data were collected using a 480channel streamer with $250 \mathrm{~m}$ near-offset and $12.5 \mathrm{~m}$ channel spacing. The record length was $12 \mathrm{~s}$ with a sampling rate of $2 \mathrm{~ms}$. In the present study, 120 near-source traces and the first $4 \mathrm{~s}$ of the data were sampled for imaging.

The data processing procedure is similar to that in Tang and Zheng (2011). One exception is that a two-layer velocity model was used during the pre-stack depth migration: $1510 \mathrm{~m} \mathrm{~s}^{-1}$ above $360 \mathrm{~m}$ and $1480 \mathrm{~m} \mathrm{~s}^{-1}$ below this depth, simplified from the CTD measurements by Nan et al. (2011). Our migration tests have shown that it is an acceptable velocity model since the artefacts along the discontinuity are untraceable and the imaging is perfect. 

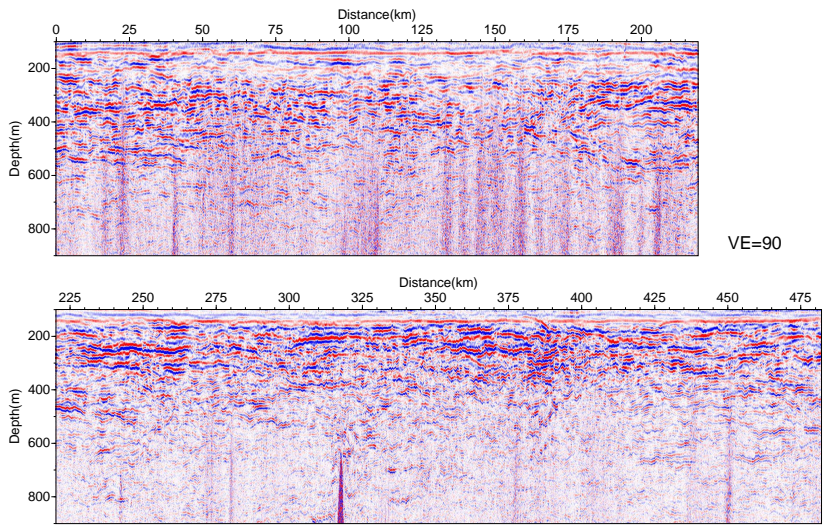

Fig. 2. Seismic images of the north (upper panel) and south (lower panel) subsections with vertical exaggeration (VE) of 90. The colour represents the relative reflection strength of the water column.

As is common with legacy seismic data, we have no in situ hydrographic data to directly support the seismic observation. Since the subsurface structures could also have considerable influence on the ocean surface that could be detected from space (Oliveira et al., 2000; Takikawa et al., 2005), the satellite altimetry data of sea surface anomaly (SLA) and their by-products of geostrophic currents produced by the AVISO are presented. Meanwhile, the daily outputs of the HYCOM, which is an eddy-resolving ( $1 / 12^{\circ}$ equatorial resolution) assimilated (including sea surface temperature, sea surface height, and in situ observations) ocean circulation model, provide convincing evidence to further study the regional mesoscale activities for the period of cruise. Vertically, the simulated HYCOM current structure above $600 \mathrm{~km}$ depth is reliable according to the previous studies (Adams et al., 2011; Xie et al., 2011).

\section{Results}

Figure 2 shows the final migration result of the seismic profile. The upper (lower) panel is the north (south) subsection. Generally, the thermohaline reflections along the profile can be clearly recognized above $800 \mathrm{~m}$ depth. Further, this informative reflection zone can be divided into two layers around $300 \mathrm{~m}$ depth: strong reflection layer above and moderate-toweak reflection layer below, corresponding to the upper and intermediate water layers, respectively. The noises dominate the profile below $800 \mathrm{~m}$ and reflections are nearly blanking (not shown below $900 \mathrm{~m}$ ), a strong indicator of the nearly homogeneous water. Such a three-layer division by seismic reflection is very similar to the hydrographic distribution of the upper water, intermediate water and deep water of the SCS (e.g. Li et al., 2002; Wang et al., 2004; You et al., 2005).

On the seismic image, the overall continuity of the finescale thermohaline reflections is poor, especially around the

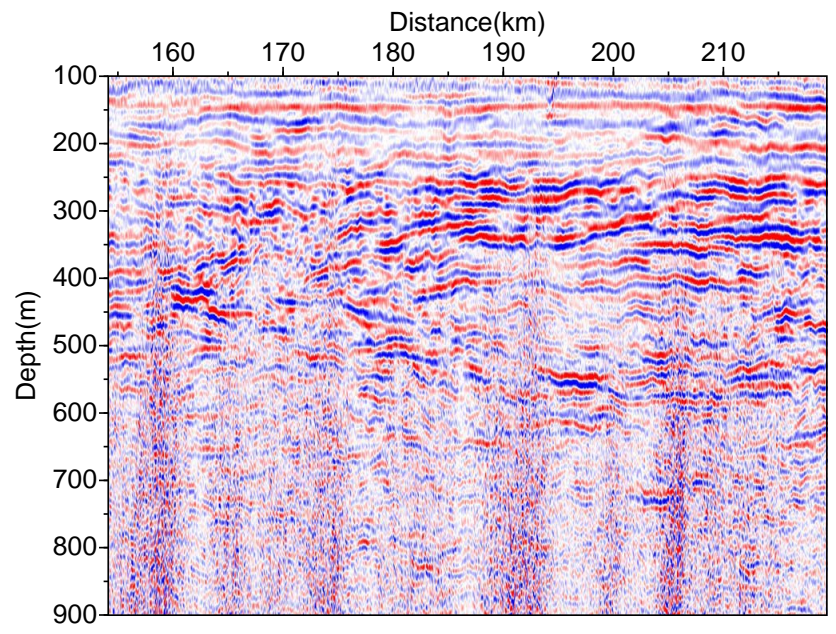

Fig. 3. Detail of the subsurface lens at the end of the north subsection shown in Fig. 2. VE $=60$.

central part of the north subsection where strong intermittency occurs. This phenomenon indicates weak or disrupted stratification, probably caused by strong mixing. In contrast, three prominent mesoscale anomalies can be recognized from the seismic image: (1) a relatively strong reflection zone down to $\sim 600 \mathrm{~m}$ at the beginning of the north subsection (ca. $0-50 \mathrm{~km}$ ), (2) a lens-like structure centred at $\sim 450 \mathrm{~m}$ at the end of the north subsection (ca. 170$220 \mathrm{~km}$ ), and (3) a narrow, north-dipping zone with strong reflection down to $\sim 350 \mathrm{~m}$ around the two-thirds point of the south subsection (ca. $380-400 \mathrm{~km}$ ). Among them, the lenslike structure is the most striking and appealing phenomenon along the transect. Its detailed structure is redrawn in Fig. 3. It should be emphasized that this subsurface lens has been firstly mentioned briefly by Huang et al. (2010). No similar subsurface structure has been reported in the southern SCS by hydrographic observations so far.

Located at $113.5^{\circ} \mathrm{E}, 11.5^{\circ} \mathrm{N}$ and centred at $450 \mathrm{~m}$, the lens-like structure occupies both subsurface and intermediate water from $\sim 250$ to $600 \mathrm{~m}$ (Fig. 3). The right periphery of the structure is missing because of the temporal termination of the seismic transect. Although the south subsection is sequential spatially with the north subsection, a time gap of $5 \mathrm{~h}$ has caused the seismic reflections to be untraceable, indicating a quick variation of the water column. From the present shape of the captured part $(\sim 50 \mathrm{~km})$ of the lens, however, an intersection diameter of $\sim 60 \mathrm{~km}$ can be estimated.

\section{Discussion}

Although the lens-like structure is clearly traceable from the seismic image, the overall reflection features between the lens-like structure and the lateral background acoustic structure are not distinct, an implication of the weak difference of the thermohaline structure between them. A chaotic zone 

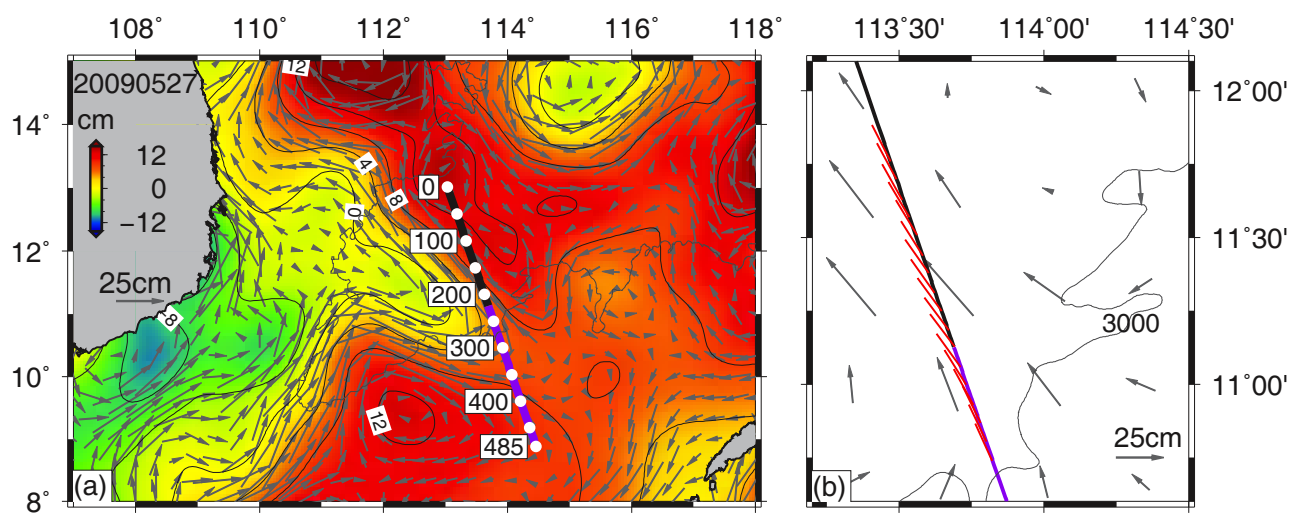

Fig. 4. (a) The SLA and the corresponding surface geostrophic currents on 27 May 2009. The seismic line and the $3000 \mathrm{~m}$ isobath are superimposed for reference. (b) Streamer feathering (red bars) due to the strong NW current (grey arrows) around the line junction.

along the north periphery of the lens, which is less well developed than Meddies, is suggestive of a mixing zone (Song et al., 2011). The reflection of the dome-shaped upper edge is extremely strong and continuous. The lower edge is also characterized by high reflectivity, which is typically deeper extended than the surrounding regions and comparable to the mesoscale anomaly at the beginning of the north subsection mentioned above. The low reflectivity in the centre is suggestive of homogeneous water or a pycnostad/thermostad there. To an extent, these reflection features of the lens are similar to some of the Meddies (e.g. Biescas et al., 2008; Pinheiro et al., 2010). Huang et al. (2010) believed that this is a representative vertical structure of an eddy. Nevertheless, we need more evidence to show whether or not the lens-like structure is a subsurface eddy because of the large similarities between the imaged current cores and subsurface eddies (Pinheiro et al., 2010; Quentel et al., 2011). If not, is it possible that a subsurface current will be responsible for the imaged mesoscale structure?

On the SLA map (Fig. 4a), we can see that the north subsection of the seismic line is located in a positive SLA region with two peaks higher than $12 \mathrm{~cm}$. The imaged lens structure is located between the southwest flank of the south peak and the northeast of the SEVOC, surrounded by a weak anticyclonic eddy and a strong northwestward geostrophic current derived from the SLA. Here, the resolution of the SLA is acceptable because of the high consistency between the SLAderived geostrophic currents and the in situ records of the streamer feathering (Fig. 4b). Considering that the subsurface eddies can have a surface signature in SLA maps sometimes (Oliveira et al., 2000; Takikawa et al., 2005), it seems possible that the imaged lens structure is interpreted as a vertical snapshot of a subsurface eddy.

However, the simulated 3-D results from HYCOM on 30 May 2009 do not support such an assumption, which is inferred just from the surface appearance of SLA. Figure 5 shows the velocity fields and their corresponding streamlines at $50 \mathrm{~m}, 100 \mathrm{~m}, 300 \mathrm{~m}$ and $600 \mathrm{~m}$ depth. The vertical section of current speeds/strengths along the seismic transect are also presented in Fig. 6a. At shallow depth, the satellite derived SLA and currents, the in situ observed streamer feathering, and the simulated velocities (Figs. 4-6) are quite consistent. At $50 \mathrm{~m}$ and $100 \mathrm{~m}$ depth (Fig. 5a, b) near the north subsection, we can see that an anticyclonic eddy corresponds well to the north peak of the positive SLA, and gradually deviates from the south peak of the positive SLA with increasing depth. The vertical depth of the eddy with current speeds larger than $5 \mathrm{~cm} \mathrm{~s}^{-1}$ is shallower than $150 \mathrm{~m}$ typically (Fig. 6a). Thus we believe that the strong baroclinic surface eddy is responsible for the positive SLA rather than the mesoscale anomalies in the subsurface layer. Meanwhile, the vertical extent of the energetic SEVOC mean flow is also shallower than $150 \mathrm{~m}$ during its juvenile stage (Figs. 5b and 6). This simulated result is reliable in that the observation of the SEVOC related eddy is shallower than $300 \mathrm{~m}$ even during the mature stage (Hu et al., 2011). Thus, a possibility that the imaged lens structure was caused from the strong baroclinic surface current of SEVOC by means of frontal instability, shedding, or flow-topography interaction can be also rejected substantially. In addition, hydrographic observations have shown that the subsurface eddy in the SCS cannot be generated by a Meddy-like generation mechanism, i.e. advected by the inflow of the Pacific intermediate waters (e.g. North Pacific Intermediate Water, Antarctic Intermediate Water). Though evidence does exist to suggest that the Pacific intermediate water can intrude into the South China Sea via the Luzon Strait, the water's low-salinity and highoxygen characteristics are not detectable in the southern part of the basin due to enhanced mixing ( $\mathrm{Qu}$ and Lindstrom, 2004; You et al., 2005).

On the contrary, there is a unique, prominent feature of the HYCOM simulated velocities between 200 to $700 \mathrm{~m}$ depth (Figs. 5c, d and 6a) where a southwest current flows along the deep basin edge of the SCS. The seismic transect just cuts across the current obliquely. The widest and strongest current flow is at $300 \mathrm{~m}$ depth and is centred at $200 \mathrm{~km}$ 

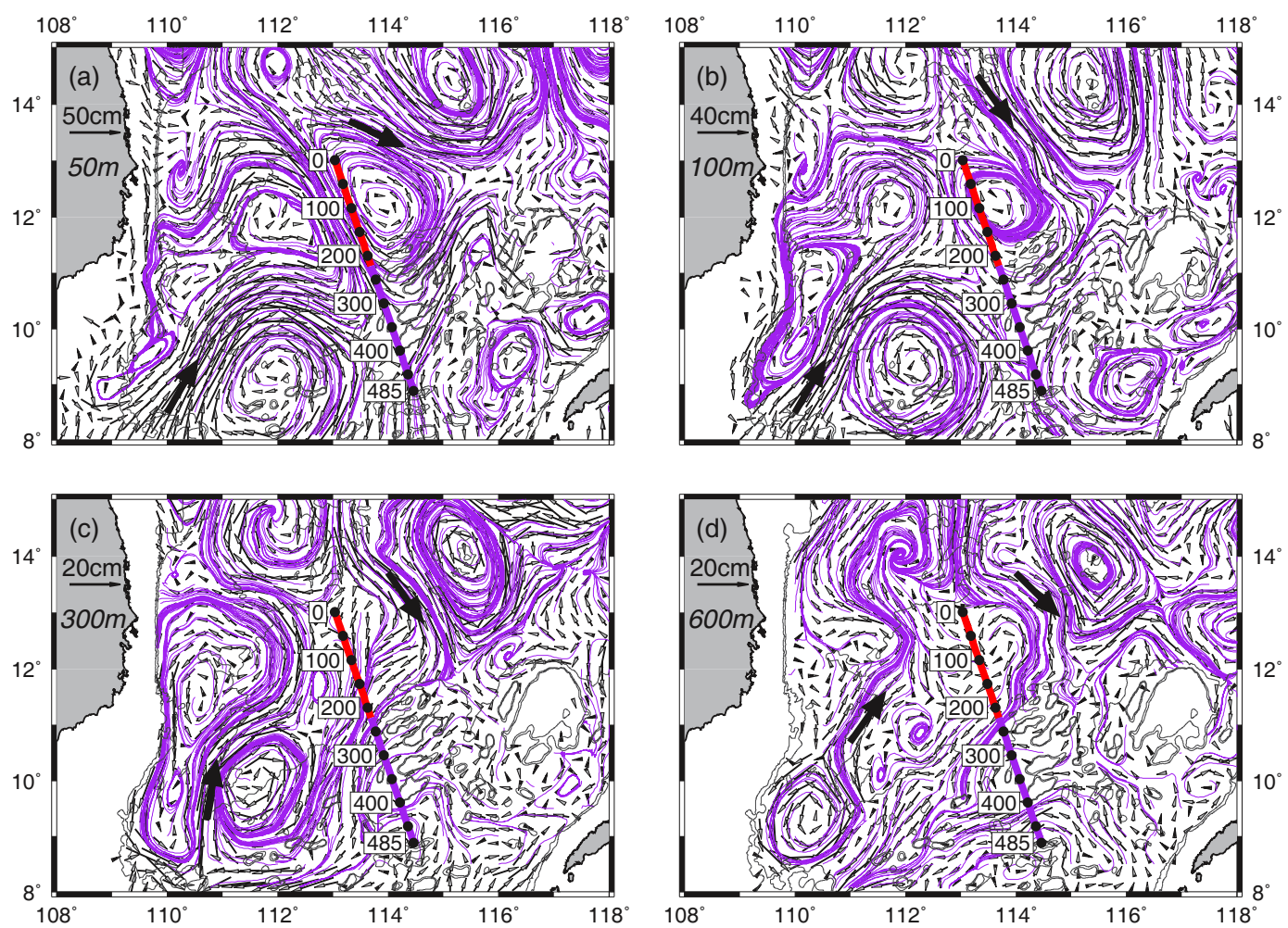

Fig. 5. HYCOM simulated velocities at different depths in the southern SCS on 30 May 2009. The purple lines are the streamlines derived from the velocities. Black arrows show the current directions at some key spots. The seismic transect with labelled distances is also superimposed.
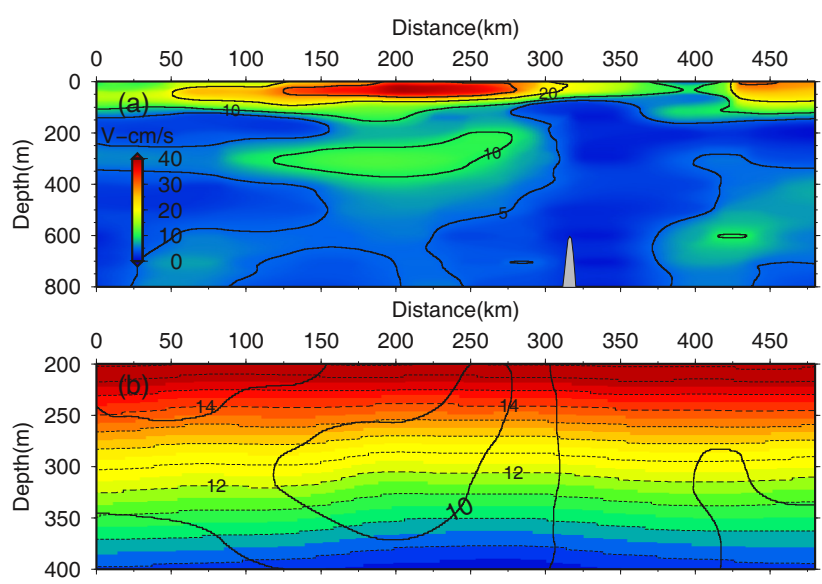

Fig. 6. Vertical sections of the HYCOM simulated current speeds (a) and temperature (b) along the seismic transect. Speeds contours in (a) are also superimposed in (b).

distance from the transect. From top to bottom, both widths and speeds of the current core are decreased gradually from $\sim 200$ to $100 \mathrm{~km}$ and $\sim 15$ to $5 \mathrm{~cm} \mathrm{~s}^{-1}$, respectively. Obviously, the location of the simulated current core matches perfectly well to the imaged subsurface lens. Further, the upward bowing of the simulated isotherms, where the thermal con-

trasts are most intense, is also consistent with the reflections of the lens structure generally (Fig. 6b). This appearance of the isotherms bending is suggestive of the geostrophic adjustment of a subsurface current (Wang, 2005). In addition, caused by the strong mixing of the vigorous current centre, a pycnostad/thermostad with slight vertical varying of the density/temperature would be formed (Lukas, 1986; Brown et al., 2001), although we could not exclude the possibility that the subsurface lens with the pycnostad/thermostad was carried by the current in the intermediate layer from somewhere else. In view of no vortex velocities simulated near the study region, we believe that the imaged lens-like structure is the snapshot of a southwestward current core as simulated. This subsurface current carries the nearby water slowly $\left(\sim 10 \mathrm{~km} \mathrm{day}^{-1}\right)$ to the study region, and thus a lens-shaped current core is captured in spite of the weak thermohaline contrast.

Figure 7 shows the daily speeds of the HYCOM results along the transect from 28 May to 2 June 2009. It is clearly seen that the strength of the simulated subsurface current is intermittent temporally. From 30 to 31 May 2009 (Fig. 7c, d), the strength of the subsurface current weakens dramatically. As aforementioned, the $5 \mathrm{~h}$ time gap at the line junction has caused the reflections to be untraceable, which is a strong indication of quick water variations. Therefore, there is a good 

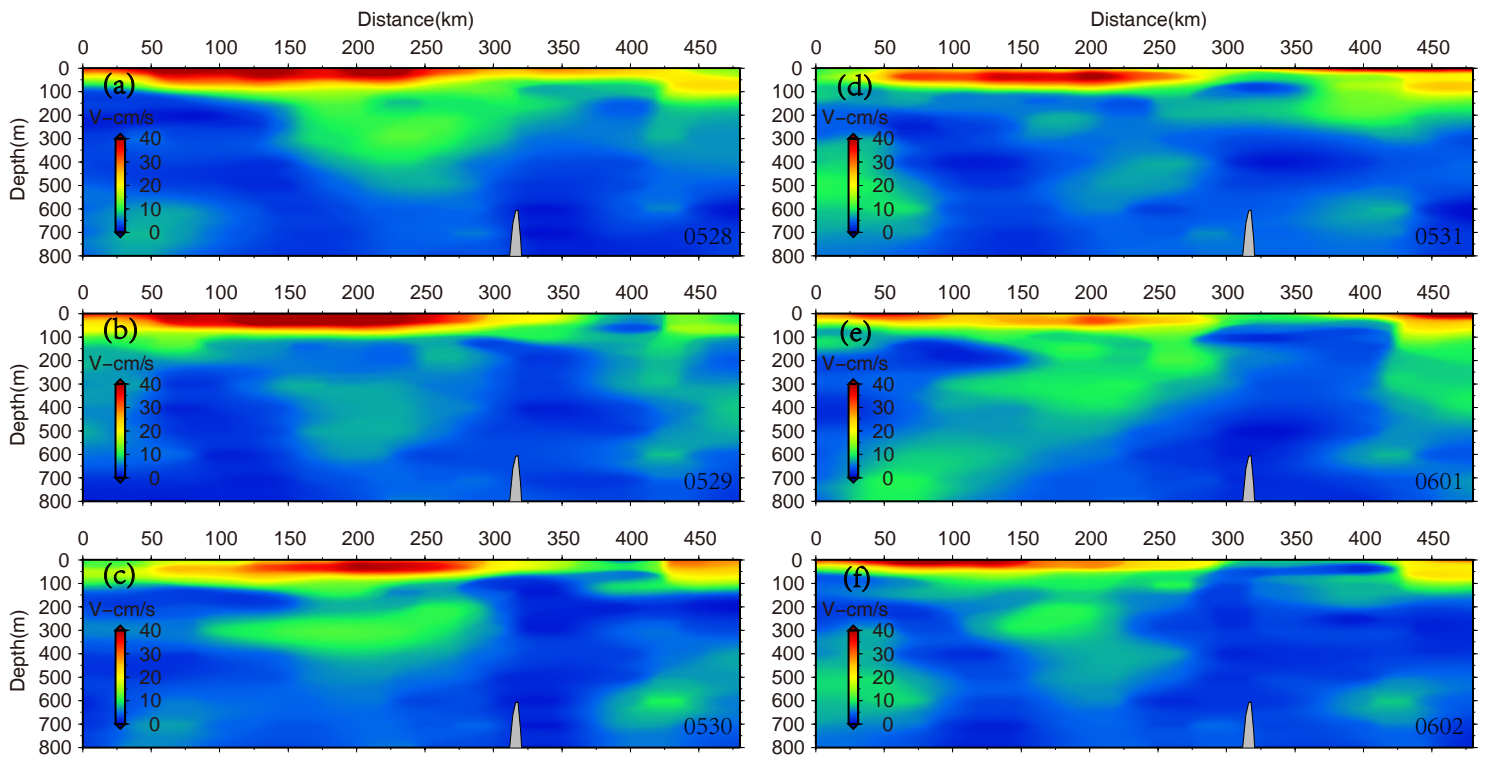

Fig. 7. Daily speeds of the HYCOM results along the transect from 28 May to 2 June 2009.

agreement between the seismic observation and the simulated result on the temporal variation of the water column. The missing right periphery of the subsurface lens might be a result of a weakened current.

Considering that the 3-D subsurface current simulated by HYCOM and the imaged subsurface lens by seismic reflection are perfectly consistent both spatially and temporally, it is more acceptable to interpret the subsurface lens as a current core, rather than a subsurface eddy. The remaining question is, what is the cause of the subsurface current along the deep basin edge? The 3-D current velocities in Fig. 5 show that an energetic cyclonic-anticyclonic eddy pair (dipole) dominates the central basin of the SCS. The upstream of the subsurface current is separated from the divergent point of the dipole. Therefore, we considered that an eddy-induced current flows southward, turns southwestward and narrows down, modified by both geostrophic effects and topography, and then runs straightforward along the deep basin edge as the highly possible process of the subsurface current. In this process, factors like vertical extent, lateral size, and strength of the eddy pair must have played important roles in the subsurface current forming, as well as the topography effects during the current marching. A preliminary census of the simulated velocity fields in the study region suggests that the subsurface currents are pervasive and the topography effect might be very important. Numerical tests would be useful to assess these factors quantitatively, but are beyond the scope of this work.

\section{Conclusions}

A legacy seismic line acquired from 30 May to 1 June 2009 in the southern SCS was reprocessed to reveal the thermohaline structure of the water column. Similar to a previous study in the northeast SCS by Tang and Zheng (2011), the water column can be divided into three layers: (1) upper layer, above $\sim 300 \mathrm{~m}$, with strong reflections; (2) intermediate layer, between 800 to $300 \mathrm{~m}$, with moderate to weak reflections; and (3) deep layer, below $\sim 800 \mathrm{~m}$, characterized by acoustic blanking. However, the fine-scale features are quite different from those in the northern SCS. The reflections are intermittent all along the profile. Internal waves are weakly developed with vertical undulations of only $5-10 \mathrm{~m}$.

The most interesting feature is the mesoscale subsurface lens located at $113.5^{\circ} \mathrm{E}, 11.5^{\circ} \mathrm{N}$. It is centred at $450 \mathrm{~m}$, occupies both the subsurface and intermediate water from 250 to $600 \mathrm{~m}$, and has an intersection diameter of $\sim 60 \mathrm{~km}$. Simulated results from HYCOM reveal an eddy-induced subsurface current flowing southwestward along the deep basin edge and suggest that the subsurface lens is a snapshot of the current core rather than a subsurface eddy. It could be misleading while the altimetric maps are related to the subsurface structures.

This study gives new insight into the dynamic processes of the subsurface and intermediate water in the SCS. The subsurface currents in the study region are pervasive but transient and affect only a small area. To quantitatively assess the factors that control the formation and evolution of the subsurface currents in the southern SCS would be an interesting work. 
Acknowledgements. We thank the $\mathrm{R} / \mathrm{V}$ Tanbao crew for the seismic data acquisition. We thank T. D. Qu for his helpful discussions. B. Ruddick and an anonymous reviewer are greatly acknowledged for their constructive comments and suggestions. The altimeter products were produced by Ssalto/Duacs and distributed by the AVISO, with support from the CNES (www.aviso.oceanobs.com/duacs). The HYCOM data are available from http://hycom.org/dataserver. This research is supported financially by the NSFC (Grants 41176026, 91228202, and 41006027) and the 973 Program (Grants 2007CB411700 and 2007CB411706).

Edited by: T. Suga

\section{References}

Adams, D. K., McGillicuddy, D. J., Zamudio, L., Thurnherr, A. M., Liang, X. F., Rouxel, O., German, C. R., and Mullineaux, L. S.: Surface-Generated Mesoscale Eddies Transport DeepSea Products from Hydrothermal Vents, Science, 332, 580-583, doi:10.1126/science.1201066, 2011.

Biescas, B., Sallares, V., Pelegri, J. L., Machin, F., Carbonell, R., Buffett, G., Danobeitia, J. J., and Calahorrano, A.: Imaging meddy finestructure using multichannel seismic reflection data, Geophys. Res. Lett., 35, L11609, doi:10.1029/2008g1033971, 2008.

Brown, E., Colling, A., Park, D., Phillips, J., Rothery, D., and Wright, J.: Chapter 5 - Other major current systems, in: Ocean Circulation, 2 Edn., edited by: Bearman, G., 143-189, 2001.

Buffett, G. G., Biescas, B., Pelegri, J. L., Machin, F., Sallares, V., Carbonell, R., Klaeschen, D., and Hobbs, R.: Seismic reflection along the path of the Mediterranean Undercurrent, Cont. Shelf Res., 29, 1848-1860, doi:10.1016/j.csr.2009.05.017, 2009.

Fang, W. D., Fang, G. H., Shi, P., Huang, Q. Z., and Xie, Q.: Seasonal structures of upper layer circulation in the southern South China Sea from in situ observations, J. Geophys. Res., 107, 3202, doi:10.1029/2002jc001343, 2002.

Gan, J., and Qu, T.: Coastal jet separation and associated flow variability in the southwest South China Sea, Deep-Sea Res Pt. I, 55, 1-19, doi:10.1016/j.dsr.2007.09.008, 2008.

Holbrook, W. S., Paramo, P., Pearse, S., and Schmitt, R. W.: Thermohaline fine structure in an oceanographic front from seismic reflection profiling, Science, 301, 821-824, 2003.

Holbrook, W. S. and Fer, I.: Ocean internal wave spectra inferred from seismic reflection transects, Geophys. Res. Lett., 32, L15604, doi:10.1029/2005g1023733, 2005.

Holbrook, W. S., Fer, I., and Schmitt, R. W.: Images of internal tides near the Norwegian continental slope, Geophys. Res. Lett., 36, L00D10, doi:10.1029/2009gl038909, 2009.

Hu, J. Y., Gan, J. P., Sun, Z. Y., Zhu, J., and Dai, M. H.: Observed three-dimensional structure of a cold eddy in the southwestern South China Sea, J. Geophys. Res., 116, C05016, doi:10.1029/2010jc006810, 2011.

Huang, X. H., Song, H. B., Dong, C. Z., and Bai, Y.: Seismic oceanography research on the eddy and water movement in the South China Sea, The Chinese Geophysics, 26th annuall meeting of Chinese Geophysics Society, Ningbo, China, abstract \#52, 2010 .
Isobe, A. and Namba, T.: The circulation in the upper and intermediate layers of the South China Sea, J. Oceanogr., 57, 93-104, 2001.

Li, F. Q., Li, L., Wang, X. Q., and Liu, C. L.: Water masses in the South China Sea and water exchange between the Pacific and the South China Sea, Journal of Ocean University of Qingdao, 1, 19-24, 2002.

Lindstrom, E., Lukas, R., Fine, R., Firing, E., Godfrey, S., Meyers, G., and Tsuchiya, M.: The Western Equatorial Pacific-Ocean Circulation Study, Nature, 330, 533-537, 1987.

Lukas, R.: The Termination of the Equatorial Undercurrent in the Eastern Pacific, Prog. Oceanogr., 16, 63-90, doi:10.1016/00796611(86)90007-8, 1986.

Montes, I., Colas, F., Capet, X., and Schneider, W.: On the pathways of the equatorial subsurface currents in the eastern equatorial Pacific and their contributions to the PeruChile Undercurrent, J. Geophys. Res.-Oceans, 115, C09003, doi:10.1029/2009jc005710, 2010.

Nakamura, Y., Noguchi, T., Tsuji, T., Itoh, S., Niino, H., and Matsuoka, T.: Simultaneous seismic reflection and physical oceanographic observations of oceanic fine structure in the Kuroshio extension front, Geophys. Res. Lett., 33, L23605, doi:10.1029/2006g1027437, 2006.

Nan, F., He, Z. G., Zhou, H., and Wang, D. X.: Three long-lived anticyclonic eddies in the northern South China Sea, J. Geophys. Res., 116, C05002, doi:10.1029/2010jc006790, 2011.

Nandi, P., Holbrook, W. S., Pearse, S., Paramo, P., and Schmitt, R. W.: Seismic reflection imaging of water mass boundaries in the Norwegian Sea, Geophys. Res. Lett., 31, L23311, doi:10.1029/2004gl021325, 2004.

Pierce, S. D., Smith, R. L., Kosro, P. M., Barth, J. A., and Wilson, C. D.: Continuity of the poleward undercurrent along the eastern boundary of the mid-latitude north Pacific, Deep-Sea Res Pt. II, 47, 811-829, 2000.

Pinheiro, L. M., Song, H. B., Ruddick, B., Dubert, J., Ambar, I., Mustafa, K., and Bezerra, R.: Detailed 2-D imaging of the Mediterranean outflow and meddies off $\mathrm{W}$ Iberia from multichannel seismic data, J. Mar. Syst., 79, 89-100, doi:10.1016/j.jmarsys.2009.07.004, 2010.

Qu, T. D., Kagimoto, T., and Yamagata, T.: A subsurface countercurrent along the east coast of Luzon, Deep Sea Res. Pt. I, 44, 413-423, 1997.

Qu, T. D.: Upper-layer circulation in the South China Sea, J. Phys. Oceanogr., 30, 1450-1460, 2000.

$\mathrm{Qu}$, T. D., and Lindstrom, E. J.: Northward intrusion of Antarctic intermediate water in the western Pacific, J. Phys. Oceanogr., 34, 2104-2118, 2004.

Quentel, E., Carton, X., Gutscher, M. A., and Hobbs, R.: Detecting and characterizing mesoscale and submesoscale structures of Mediterranean water from joint seismic and hydrographic measurements in the Gulf of Cadiz, Geophys. Res. Lett., 37, L06604, doi:10.1029/2010g1042766, 2010.

Quentel, E., Carton, X., and Gutscher, M. A.: Structure and temporal variability of Mediterranean Water in hydrological and marine seismic data south of Portimao Canyon (Gulf of Cadiz), from 1999 to 2002, Int. J. Geosci., 2, 185-194, doi:10.4236/ijg.2011.23020, 2011.

Ruddick, B., Song, H. B., Dong, C. Z., and Pinheiro, L.: Water column seismic images as maps of temperature gradient, Oceanog- 
raphy, 22, 192-205, 2009.

Sheen, K. L., White, N. J., and Hobbs, R. W.: Estimating mixing rates from seismic images of oceanic structure, Geophys. Res. Lett., 36, L00D04, doi:10.1029/2009g1040106, 2009.

Song, H. B., Pinheiro, L. M., Ruddick, B., and Teixeira, F. C.: Meddy, spiral arms, and mixing mechanisms viewed by seismic imaging in the Tagus Abyssal Plain (SW Iberia), J. Mar. Res., 69, 827-842, 2011.

Takikawa, T., Ichikawa, H., Ichikawa, K., and Kawae, S.: Extraordinary subsurface mesoscale eddy detected in the southeast of Okinawa in February 2002, Geophys. Res. Lett., 32, L17602, doi:10.1029/2005g1023842, 2005.

Tang, Q. S. and Zheng, C.: Thermohaline structures across the Luzon Strait from seismic reflection data, Dyn. Atmos. Oceans, 51, 99-113, doi:10.1016/j.dynatmoce.2011.02.001, 2011.

Vsemirnova, E. A., Hobbs, R. W., and Hosegood, P.: Mapping turbidity layers using seismic oceanography methods, Ocean Sci., 8, 11-18, doi:10.5194/Os-8-11-2012, 2012.

Wang, C. Z.: Subthermocline tropical cells and equatorial subsurface countercurrents, Deep-Sea Res Pt. I, 52, 123-135, doi:10.1016/j.dsr.2004.08.009, 2005.
Wang, D. X., Chen, J., Chen, R. Y., Zhu, B. C., Guo, X. G., Xu, J. D., and Wu, R. S.: Hydrographic and circulation characteristics in middle and southern South China sea in summer, 2000, Oceanologia et Limnologia Sinica, 35, 97-109, 2004. (in Chinese)

Wang, G. H., Su, J. L., and Chu, P. C.: Mesoscale eddies in the South China Sea observed with altimeter data, Geophys. Res. Lett., 30, 2121, doi:10.1029/2003gl018532, 2003.

Wang, G. H., Chen, D. K., and Su, J. L.: Generation and life cycle of the dipole in the South China Sea summer circulation, J. Geophys. Res., 111, C06002, doi:10.1029/2005jc003314, 2006.

Xie, L. L., Tian, J. W., Zhang, S. W., Zhang, Y. W., and Yang, Q. X.: An anticyclonic eddy in the intermediate layer of the Luzon Strait in Autumn 2005, J. Oceanogr., 67, 37-46, doi:10.1007/s10872011-0004-9, 2011.

Xiu, P., Chai, F., Shi, L., Xue, H. J., and Chao, Y.: A census of eddy activities in the South China Sea during 1993-2007, J. Geophys. Res., 115, C03012, doi:10.1029/2009jc005657, 2010.

You, Y. Z., Chern, C. S., Yang, Y., Liu, C. T., Liu, K. K., and Pai, S. C.: The South China Sea, a cul-de-sac of North Pacific Intermediate Water, J. Oceanogr., 61, 509-527, 2005. 